InterSedes, Revista electrónica de las sedes regionales de la Universidad de Costa Rica, ISSN 2215-2458, Vol XXI, Número 43, Enero - Julio, 2020.

10.15517/isucr.v21i43.41980 | intersedes.ucr.ac.cr | intersedes@ucr.ac.cr

\title{
FILOSOFÍA DE LA HISTORIA EN CARMEN LYRA Y RODOLFO CERDAS CRUZ
}

\section{PHILOSOPHY OF HISTORY IN CARMEN LYRA AND RODOLFO CERDAS CRUZ}

Roberto Herrera -Zúñiga ${ }^{1}$

\begin{tabular}{|l|l} 
Recibido: 14.07 .19 & Aprobado: 30.04.20
\end{tabular}

DOI: $10.15517 /$ isucr.v21i43.41980

\section{Resumen}

El artículo busca ser una crítica a los elementos ideológicos presentes en las lecturas históricas de Carmen Lyra y Rodolfo Cerdas Cruz, encontrando las marcas y criticando los rastros y registros de la subjetividad eurocéntrica presente en estos autores. Sostenemos que estas marcas son producidas por la afiliación de estos autores a los tópicos básicos del DIAMAT soviético y del comunismo "a la tica".

Palabras claves: Rodolfo Cerdas Cruz; Carmen Lyra; filosofía de la historia; criticas; comunismo a la tica.

\begin{abstract}
This article seeks to provide a critique of the ideological elements present in the reading of history by Carmen Lyra and Rodolfo Cerdas Cruz, finding the marks and criticizing the traces and records of the eurocentric subjectivity present in the two authors. We maintain that these marks are produced by the affiliation of these authors with the basic themes of the Soviet DIAMAT and communism "a la tica.".
\end{abstract}

Keywords: Rodolfo Cerdas Cruz; Carmen Lyra; philosophy of history; criticism of communism "a la tica".

"Solíamos preguntarle a los ancianos... ¿Qué trajeron los españoles cuando vinieron? A Dios, espejos y la cruz en el cielo. Todos símbolos idealistas. ¿Pero qué solían adorar ustedes antes de que llegaran? El agua, la tierra, el sol y el maíz, todos factores materiales de las relaciones de producción."

Efraín Reyes Maaz, dirigente Q’echi’ del Partido Guatemalteco del Trabajo (1950s-60s)

\footnotetext{
${ }^{1}$ Profesor en la Escuela de Filosofía de la Universidad de Costa Rica, San Pedro, San José, Costa Rica. Escuela de Trabajo Social, Universidad de Costa Rica, Sede de Occidente, San Ramón, Alajuela, Costa Rica.

Email: xherrera16@yahoo.com
} 
Teoría de la historia y filosofía de la historia. Aclaraciones conceptuales

Filosofía de la historia, DIAMAT y comunismo "a la tica"

Creemos necesario hacer algunas aclaraciones conceptuales antes de ingresar a comparar las filosofías de la historia presentes en los textos de Rodolfo Cerdas Cruz y Carmen Lyra. Siguiendo a Gallardo, consideramos a la filosofía como una región ideológica ${ }^{2}$ y por lo tanto debemos distinguir claramente entre filosofía de la Historia y teoría de la historia, para Gallardo la diferencia entre una teoría de la historia y una filosofía de la Historia:

"no está en la verdad absoluta de la primera y en el error también absoluto de la segunda, sino en la tensión (heurística: de búsqueda, de interpretación, de explicación) que el discurso conceptual de la primera establece con lo real-social, que es su raíz y a la que intenta pensar, y el carácter imaginarioespeculativo, de sentido común espuriamente teorizado, de la segunda. Dicho de otra forma: una teoría de la historia está en tensión y lucha contra las ideologías de la historia. Las filosofías de la Historia son ideologías de la historia" (Gallardo, 1993,153).

Las filosofías de la Historia de la modernidad, necesariamente están cargadas con dos seudo conceptos: el evolucionismo y el dualismo ${ }^{3}$. La principal filosofía de la Historia en el campo de la

\footnotetext{
2 "todo grupo humano se entrega a sí mismo una concepción o visión del mundo. Con otro lenguaje podemos decir que toda formación social posee una concepción ideológica de sí misma, es decir una sistematización más o menos explícita de sus valores y representaciones dominantes y cuyo objeto es asegurar la cohesión social. Desde este punto de punto de vista la filosofía es una región de la ideología, una región ideológica" (1980, 70). Para Gallardo la filosofía necesariamente es "la forma más alta de la enajenación ideológica" (73). "El filosofar muestra así posibles raíces en la "contemplación”, es decir en la pura descripción pseudo conceptual, o en la conceptualización sedicientemente teórica, pero en verdad especulativa, es decir incapaz de dar cuenta de su raíz histórica, o en la "transformación”, para la cual debe dar cuenta de sí, histórica y socialmente, es decir debe dar cuenta de la necesidad y posibilidad de ser teoría o pensamiento conceptual" (65).

3 "Esa perspectiva binaria, dualista, de conocimiento, peculiar del eurocentrismo, se impuso como mundialmente hegemónica en el mismo cauce de la expansión del dominio colonial de Europa sobre el mundo. No sería posible explicar de otro modo, satisfactoriamente en todo caso, la elaboración del eurocentrismo como perspectiva hegemónica de conocimiento, de la versión eurocéntrica de la modernidad y sus dos principales mitos fundantes: uno, la ideaimagen de la historia de la civilización humana como una trayectoria que parte de un estado de naturaleza y culmina en Europa. Y dos, otorgar sentido a las diferencias entre Europa y no-Europa como diferencias de naturaleza (racial) y no de historia del poder. Ambos mitos pueden ser reconocidos, inequívocamente, en el fundamento del evolucionismo y del dualismo, dos de los elementos nucleares del eurocentrismo." (Quijano, 2000,296-297).
} 
izquierda política moderna ${ }^{4}$ fue el DIAMAT de matriz soviética ${ }^{5}$ y es sin duda alguna la matriz fundamental del pensamiento de la izquierda costarricense y por ende del comunismo "a la tica"6. Reseñemos como los tópicos básicos del DIAMAT aparecen en los principales intelectuales orgánicos ${ }^{7}$ de la izquierda política costarricense a lo largo de varias décadas hasta llegar al presente. Por ejemplo, aparecen en un discurso efectuado por Manuel Mora en 1937, donde este explicaba que para el marxismo: "La sociedad es un organismo vivo de la Naturaleza, que evoluciona de conformidad con leyes propias" $(1980,66)$.

Eduardo Mora, su hermano, ya en los años setentas señalaba en su Introducción al marxismoleninismo que:

\footnotetext{
4 "La moderna actitud 'de izquierda' se autodetermina mediante la articulación e integración de varios factores: discernimiento (sociohistórico) con cuidado de sí, comunicación y propuesta a otros, reconocimiento de los otros como diversos legítimos (no elimina la enemistad ni el conflicto), programa, imaginario utópico (horizonte de esperanzas ligadas a transformaciones cualitativas por liberadoras). Todo ello supone expresiones organizativas que procuran ser eficaces. También que las izquierdas se relacionan con procesos y constituyen apuestas." (Gallardo, 2009)

${ }^{5}$ La exposición fundamental del DIAMAT, se encuentra en el texto: El materialismo dialéctico y el materialismo histórico de José Stalin, este texto es redactado en 1938 y se popularizó pues era el capítulo IV de la historia oficial del PCUS, de allí se trasformó en modelo oficial de los Manuales soviéticos, tanto de los que pretendían explica el DIAMAT, como de los manuales de otras ramas del conocimiento humano (Kohan, 2003, 43-53). Coincidimos con Néstor Kohan $(2003,41)$ cuando señala que el DIAMAT partía de una "metafísica materialista" y de allí desarrollaba/deducía su "aplicación" al ámbito histórico social. "En esta deducción-aplicación va implícita la naturalización de lo social" (...) Pues si en la naturaleza rigen leyes absolutas y los fenómenos se comportan de manera totalmente irreversible y necesaria, entonces en el terreno socio-histórico de deducción-aplicación "la lucha de clases del proletariado constituye un fenómeno perfectamente natural e inevitable". Tal necesidad expresada en las férreas leyes de la sociedad, gracias a las cuales es posible según esta teoría que haya "ciencia" en el estudio de esta, permite que el cuerpo científico social tenga la misma precisión que las ciencias naturales; por ejemplo, que la biología" (2003, 41).

${ }^{6} \mathrm{He}$ analizado esta peculiar recepción del marxismo en Costa Rica en otros trabajos: La producción socio histórica del comunismo a la tica (2008); Pensar radical, pensar colonizado. Una mirada al marxismo costarricense (2009) y en la serie de artículos 8 preguntas sobre el comunismo "a la tica" publicadas en las revistas digitales Paquidermo, Amauta y Socialismo Hoy. A grandes rasgos la idea del comunismo "a la tica" supone una ideología/estrategia que justifique un marxismo "criollo" respetuoso de las tradiciones y políticas nacionales entre ellas: la "fiesta" electoral, el institucionalismo y la religión católica.

${ }^{7}$ La categoría intelectual orgánico la entendemos tal cual la caracterizó Antonio Gramsci. Para el reconocido marxista italiano: "Cada grupo social, al nacer en el terreno originario de una función esencial en el mundo de la producción económica, se crea conjunta y orgánicamente uno o más rangos de intelectuales que le dan homogeneidad y conciencia de la propia función, no sólo en el campo económico, sino también en el social y en el político" $(1967,21)$. En la concepción gramsciana: "Cada hombre, considerado fuera de su profesión, despliega cierta actividad intelectual, es decir, es un "filósofo", un artista (...) participa en una concepción del mundo, tiene una consciente línea de conducta moral, y por eso contribuye a sostener o a modificar una concepción del mundo, es decir, a suscitar nuevos modos de pensar." (26) Por lo tanto: "Todos los hombres son intelectuales, podríamos decir, pero no todos los hombres tienen en la sociedad la función de intelectuales. Cuando se distingue entre intelectuales y no intelectuales, en realidad sólo se hace referencia a la inmediata función social de la categoría profesional de los intelectuales" (26)“el obrero (...), por ejemplo, no se caracteriza específicamente por el trabajo manual o instrumental, sino por la situación de ese trabajo en determinadas condiciones y en determinadas relaciones sociales (...) no existe trabajo puramente físico (...) [en] cualquier trabajo físico; aunque se trate del más mecánico y degradado, siempre existe un mínimo de calidad técnica, es decir un mínimo de actividad creativa" (25).
} 
Así como las leyes mediante las cuales se rigen los fenómenos de la naturaleza determinan que después de la noche llega el día, así las leyes mediante las cuales se rige el desarrollo de la sociedad determinan que después del capitalismo llega el socialismo, y que después de su primera fase la sociedad debe pasar a la segunda y última: el comunismo (1970, 14$15)$.

Y finalmente José Merino, yerno del segundo, actual presidente del Frente Amplio y heredero teórico-político de esta tradición, exponiendo su interpretación de Marx, señala a mediados de los años noventa que:

Marx concibió el movimiento social como un proceso histórico-natural regido por leyes que no sólo son independientes de la voluntad, la conciencia y la intención de los hombres, sino que además determinan su voluntad, conciencia e intención. Conocer esas leyes, puede ayudar a los hombres a acelerar los procesos históricos, pero nunca a saltar ni a descartar etapas o frases. (Merino, 1996, 89).

Vemos que aparecen en estos intelectuales orgánicos casi todos los tópicos fundamentales del DIAMAT: metafísica naturalista, organicismo positivista, determinismo fatalista, evolucionismo y una metafísica de la Historia sin sujeto.

La concepción materialista de la historia.

Existe mucha confusión en el campo intelectual producida por el hecho que la mayoría de la izquierda política suscribiera las concepciones filosóficas del DIAMAT, por ello creemos prudente reconstruir con alguna precisión en qué consiste exactamente la concepción materialista de la historia y de allí qué conclusiones teóricas y políticas se derivan. Si se quiere exponer la concepción materialista de la historia, creemos que primero se debe tomar en cuenta la advertencia que realizara Marx en el inicio del 18 Brumario de Luis Bonaparte, texto importante pues es justamente una aplicación del método materialista histórico a un determinado acontecimiento político de una determinada formación económico social, allí Marx señala:

Los hombres hacen su propia historia, pero no la hacen a su libre arbitrio, bajo circunstancias elegidas por ellos mismos, sino bajo aquellas circunstancias con que se encuentran directamente, que existen y les han sido legadas por el pasado. La tradición de todas las generaciones muertas oprime como una pesadilla el cerebro de los vivos. (Marx, 1978,404). 
Pero ¿cómo es precisamente que son legadas estas circunstancias? y más aún ¿cuál es el carácter de estas circunstancias? Haciendo una generalización en un nivel de abstracción muy alto sobre cómo opera este proceso, Marx señala en el Prólogo a la Contribución a la Crítica de la Economía Política, la que se considera la exposición más general del materialismo histórico:

En la producción social de su vida los hombres establecen determinadas relaciones necesarias e independientes de su voluntad, relaciones de producción que corresponden a una fase determinada de desarrollo de sus fuerzas productivas materiales. El conjunto de estas relaciones de producción forma la estructura económica de la sociedad, la base real sobre la que se levanta la superestructura jurídica y política y a la que corresponden determinadas formas de conciencia social. El modo de producción de la vida material condiciona el proceso de la vida social política y espiritual en general. No es la conciencia del hombre la que determina su ser sino, por el contrario, el ser social es lo que determina su conciencia. Al llegar a una fase determinada de desarrollo las fuerzas productivas materiales de la sociedad entran en contradicción con las relaciones de producción existentes o, lo que no es más que la expresión jurídica de esto, con las relaciones de propiedad dentro de las cuales se han desenvuelto hasta allí. De formas de desarrollo de las fuerzas productivas, estas relaciones se convierten en trabas suyas, y se abre así una época de revolución social (Marx, 1978,517-518).

Ahora, la comprensión cabal de los mecanismos objetivos que caracterizan una determinada forma de desarrollo social, no implican bajo ninguna circunstancia el fatalismo y el evolucionismo típico de las filosofías de la Historia, no hay mecanismos o entidades supra históricos que sobredeterminen fatalmente la actividad histórica de los hombres, todo lo contrario, Marx fue categóricamente enfático en el sentido que la "Historia" no hace nada, este énfasis se puede encontrar en sus obras tempranas, pero también en sus obras de madurez, veamos por ejemplo como se planteaba el problema en 1844, señala Marx:

Una vez que el hombre ha sido reconocido como la esencia, como la base de toda actividad humana y de toda relación humana, únicamente la crítica puede inventar todavía nuevas categorías y re transformar, así como lo hace precisamente, al hombre en una categoría y hasta en el principio de toda una serie de categorías, recurriendo de esta manera a la única escapatoria que le queda aún a la "inhumanidad" teológica, acosada y perseguida. La historia no hace nada, "no posee una riqueza inmensa", "no libra combates"! Ante todo es el hombre, el hombre real y vivo quien hace todo eso y realiza combates; estemos seguros que no es la historia la que se sirve del hombre como de un medio para realizar — como si ella 


\section{fuera un personaje particular-sus propios fines; no es más que la actividad del hombre que persigue sus objetivos. (1971, 112)}

La idea de un proceso histórico sin sujeto, naturalizado y objetivizado de manera metafísica, ya había sido recusado por Engels, el cual en vida había logrado entrever el inicio de la deformación manualesca del marxismo, en 1890 en una carta personal a J. Bloch señalaba:

Según la concepción materialista de la historia, el factor que en última instancia determina la historia es la producción y la reproducción de la vida real. Ni Marx ni yo hemos afirmado nunca más que esto. Si alguien lo tergiversa diciendo que el factor económico es el único determinante, convertirá aquella tesis en una frase vacua, abstracta, absurda. La situación económica es la base, pero los diversos factores de la superestructura que sobre ella se levanta --las formas políticas de la lucha de clases y sus resultados, las Constituciones que, después de ganada una batalla, redacta la clase triunfante, etc., las formas jurídicas, e incluso los reflejos de todas estas luchas reales en el cerebro de los participantes, las teorías políticas, jurídicas, filosóficas, las ideas religiosas y el desarrollo ulterior de éstas hasta convertirlas en un sistema de dogmas-- ejercen también su influencia sobre el curso de las luchas históricas y determinan, predominantemente en muchos casos, su forma. Es un juego mutuo de acciones y reacciones entre todos estos factores, en el que, a través de toda la muchedumbre infinita de casualidades (es decir, de cosas y acaecimientos cuya trabazón interna es tan remota o tan difícil de probar, que podemos considerarla como inexistente, no hacer caso de ella), acaba siempre imponiéndose como necesidad el movimiento económico. De otro modo, aplicar la teoría a una época histórica cualquiera sería más fácil que resolver una simple ecuación de primer grado $(1975,74)$.

Finalmente podemos señalar que en el marxismo clásico, siempre se señaló con claridad como el "progreso" entendido como una evolución lineal, necesaria y repetitiva era un ideologema del pensamiento burgués. Los marxistas clásicos han señalando permanentemente el carácter desigual y combinado del desarrollo social y de las formaciones políticas ${ }^{8}$.

La crítica del ideologema del progreso burgués, no es únicamente una crítica al fatalismo y al evolucionismo determinista mecánico, que es tal vez la dimensión más sencilla de observar en

\footnotetext{
8 "Las leyes de la historia no tienen nada de común con el esquematismo pedantesco. El desarrollo desigual, que es la ley más general del proceso histórico, no se nos revela, en parte alguna, con la evidencia y la complejidad con que la patentiza el destino de los países atrasados. Azotados por el látigo de las necesidades materiales, los países atrasados vense obligados a avanzar a saltos. De esta ley universal del desarrollo desigual de la cultura se deriva otra que, a falta de nombre más adecuado, calificaremos de ley del desarrollo combinado, aludiendo a la aproximación de las distinta etapas del camino y a la confusión de distintas fases, a la amalgama de formas arcaicas y modernas. Sin acudir a esta ley, enfocada, naturalmente, en la integridad de su contenido material, sería imposible comprender la historia de Rusia ni la de ningún otro país de avance cultural rezagado, cualquiera que sea su grado.” (Trotsky, 1932).
} 
los textos del marxismo clásico, sino que también es una crítica al subjetivismo y voluntarismo que supone que los cambios históricos y políticos se pueden realizar primordialmente sobre la base de voluntad política.

León Trotsky en una crítica a estas dos dimensiones políticas presentes en la esquemática teórica del DIAMAT soviético señalaba con agudeza que justamente el marxismo como teoría de la historia y como estrategia política es una permanente oposición/tensión entre el fatalismo y el voluntarismo como filosofías de la Historia, pero también una superación de estas dos falsas alternativas, señala Trotsky en su libro "Stalin, el gran organizador de derrotas":

"La escolástica no quiere comprender que entre el determinismo mecánico (fatalismo) y el arbitrario subjetivo está la dialéctica materialista. El fatalismo dice: "Cuando se está tan atrasado, se haga lo que se haga, no se llegará a ninguna parte." El subjetivismo vulgar dice: “Milagro!, basta con quererlo y se construye el socialismo.” El marxismo dice: "Si tomamos conciencia de la interdependencia que existe entre las condiciones mundiales y el estado retrasado del país, por medio de una política correcta nos levantaremos, nos reforzaremos y nos integraremos en la revolución mundial victoriosa." (1929).

\section{La Filosofía de la Historia en Carmen Lyra}

Tendríamos que señalar que Carmen Lyra tiene la peculiaridad dentro de la plana mayor de los intelectuales orgánicos del PVP, que ella arriba a conclusiones comunistas después de pasar por una evolución ideológica desde el romanticismo anticapitalista ${ }^{9}$ (tipo Ariel de José Enrique Rodo) pasando por el nacionalismo de capas medias del APRA ${ }^{10}$. A diferencia de otros intelectuales (García Monge, José María Zeledón, Omar Dengo) que compartieron con Carmen Lyra, estos mismos proyectos políticos, Carmen Lyra fue la única de esta generación intelectual que decidió sumarse al proyecto del PC CR.

\footnotetext{
9 "Frente a la escalada irresistible del capitalismo, al despliegue invasivo de la civilización científica y técnica, de la gran producción industrial, del universo de la mercancía y de los valores mercantiles, se produce -en diversos medios sociales y, particularmente, en la intelligentsia tradicional- una reacción cultural (unas veces desesperada y trágica, otras resignada) que puede designarse como romanticismo anticapitalista" (Lowy, 1997, 30).

${ }^{10} \mathrm{El}$ marxismo latinoamericano va a nacer no solo en polémica contra el imperialismo y las clases dominantes criollas, sino contra el incipiente nacionalismo burgués representado por el movimiento aprista de Haya de la Torre. "El APRA había surgido en 1925 como una propuesta de frente único del ala izquierda de los estudiantes e intelectuales de la Reforma Universitaria y del movimiento obrero. En 1927, su principal dirigente, Haya de la Torre, se define contra el comunismo y postula al APRA como el "Kuomintang latinoamericano", es decir como un partido nacionalista con una estrategia de conciliación de clases, a partir de lo cual la "vanguardia" que había surgido del movimiento obrero de 1919 y de la Reforma Universitaria, y que había encontrado su expresión cultural en la revista Amauta, se divide claramente en un ala nacionalista pequeño burguesa (Haya de la Torre) y otra socialista que defiende el marxismo y la perspectiva de la revolución proletaria (Mariátegui).” (Dal Maso, 2007,117).
} 
Iván Molina ha señalado con bastante claridad, lo que creemos que es el elemento fundamental para señalar los límites intelectuales de esta generación romántica anticapitalista. El discurso y las posiciones políticas que elaboraron estos intelectuales sobre la llamada cuestión social:

Tenía una doble cara, una potencialmente explosiva, y otra muy identificada con la ideología liberal del progreso. El lado subversivo de sus escritos (...) denuncia la explotación laboral, el crecimiento de la pobreza, de las campañas electorales como farsas al servicio de los poderosos, y del imperialismo estadounidense" (...) "El perfil no contestatario de estos radicales se desprendía de su énfasis en que los sectores populares de la ciudad y el campo, para alcanzar su plenitud física y espiritual, debían ser redimidos mediante una educación apropiada, que sería proporcionada por esos mismos jóvenes. Este ambicioso proyecto de ingeniería social, al tiempo que revalorizaba la función de los intelectuales, sirvió de base para que los izquierdistas de comienzos del siglo $\mathrm{XX}$, se integraran poco a poco en el programa civilizador de los liberales. (Molina, 2000,24).

Una de las primeras cosas que llama la atención de la filosofía de la Historia de Carmen Lyra, es que explica los distintos regímenes sociales costarricenses ${ }^{11}$ como una sucesión necesaria y "pura" que sobrevienen unos a otros hasta llegar a la independencia (comunismo primitivo, esclavismo, feudalismo, capitalismo, eventualmente regreso del comunismo científico).

En la exposición se encuentra la contradicción que inicia su exposición con el tipo de régimen social que tenían los indios (comunismo primitivo), pero señala que Costa Rica inicia como país en 1502, con la llegada de Colón (1972, 303). Es evidente la doble fractura, pues no considera las sociedades precolombinas como una de las formas previas y que combinadas con el proceso de conquista europea hicieron emerger la sociedad colonial, sino que el efecto es el corte, pero este corte es también metafísico pues en 1502, tampoco existía Costa Rica, cuya creación propiamente dicha es una construcción del siglo XIX. Es decir, aquí encontramos evolucionismo y cortes abstractos de la historia para poder colocarla en sucesión necesaria.

\footnotetext{
${ }^{11}$ Carmen Lyra usa un concepto bastante ambiguo régimen y parece al utilizarlo que esta mezclando dos conceptos distintos del arsenal teórico del marxismo: Modo de producción y formación económico-social. "Los marxistas siempre hemos entendido que el Modo de producción es la interrelación entre las fuerzas productivas y las relaciones de producción, y que el Modo de Producción se refiere estrictamente a la estructura económica de la sociedad. (...) El Modo de Producción no abarca la totalidad de las manifestaciones de la sociedad (...). La formación social es también una categoría teórica [que permite] comprender la totalidad de la sociedad, la interinfluencia entre las llamadas estructura y superestructura. Sólo a la luz de la categoría teórica de Formación Social se pueden explicar las tendencias sociales, políticas, ideológicas y, sobre todo, la lucha de clases que es lo medular del materialismo histórico" (Vitale, 1974).
} 
Lyra inicia su exposición caracterizando el régimen social de los pueblos originarios, señala que los indios vivían en el comunismo primitivo $^{12}$, tal cual lo describiera Engels en El origen de la familia, la propiedad privada y el Estado.

Curiosamente aquí se mezcla un forzamiento de la explicación clásica del DIAMAT, según la cual siempre y en todo lugar se inicia el proceso de evolución histórica con el comunismo primitivo, esta operación intelectual de Lyra evidentemente tiene el objetivo de "hacer calzar" la historia costarricense con la Historia Mundial en clave DIAMAT, pero también aparece en el marco de la misma explicación los tópicos del "estado naturaleza" es decir el absoluto atraso social y moral.

Por ejemplo, Lyra señala: "las tribus indígenas que en Costa Rica vivían en el régimen llamado comunismo primitivo, trabajaban en común las tierras" (1972, 305). Su economía se basaba en "la propiedad colectiva de la tierra y en la cooperación común del trabajo" (328). Esto dicho en un tono que se estima positivo. Pero en otros pasajes indica que los indios: "se hacían constantemente la guerra (...) los que salían victoriosos reducían a la esclavitud a los prisioneros" (304) y que "adoraban muchos dioses, que por lo general representan fenómenos de la naturaleza (...)" (305). De los chorotegas señala que: "como todos los indios de origen mexicano, comían carne humana que consideraban un manjar" (316) y que "se casaban con una sola mujer, pero los caciques tenían varias" (317), siguiendo a Bartolomé de las Casas indica que los indios eran "la mejor gente que hasta allí habían hallado" (316).

Podríamos ver varios niveles ideológicos en estas caracterizaciones. El primero y el más importante el inicio de la Historia, que en el caso de Lyra, no es un corte conceptual para lograr iniciar en un punto en la exposición, sino que es un corte real (o que se pretende real) de la Historia costarricense que inicia en 1502 y le suceden fases nítidamente diferenciables producto de las características del régimen social.

Las etapas que están antes que comience la Historia, son estado de naturaleza como se ve en los tópicos sobre la ausencia de propiedad privada, de religión abstracta, de familia patriarcal y por supuesto la ausencia de límites morales (poligamia, antropofagia), estas ausencias claramente

\footnotetext{
12 "El Modo de producción Comunal de nuestras sociedades aborígenes y el Modo de Producción Asiático de las culturas inca y azteca fue cortado drásticamente por un factor exógeno: la conquista española y portuguesa. La colonización no estableció un modo preponderante de producción sino variadas Relaciones de Producción precapitalistas (encomienda, esclavitud, aparcería, medianería, inquilinaje, etc.) y embriones capitalistas, como el salariado minero, en una economía primaria-exportadora, agropecuaria y minera, integrada al mercado mundial capitalista en formación." (Vitale, 1974)
} 
resaltadas funcionan como un recurso de animalización que puede producir tanto miedo, como ternura, para esto sirve el comentario de las Casas sobre la bondad indígena que reproduce Lyra.

La animalización como recurso ideológico, es sumamente productiva pues permite legitimar múltiples formas de dominación: el exterminio (bestias salvajes), el tutelaje pastoral (buen salvaje), la conversión filantrópica (salvamos sus almas) y la frialdad tecnoburocrática (administramos sus cuerpos como fuerza de trabajo). Lo que evidentemente no permite el recurso ideológico del estado naturaleza es el reconocimiento y mucho menos un reconocimiento político como alternativa societal.

$\mathrm{Si}$ algo es notable en el texto de Lyra, es que no hay ninguna pregunta sociológica por entender ¿Qué resultado nuevo produjo la mezcla violenta de la conquista y la colonia con las supervivencias del viejo orden originario? y ¿Qué es lo que volvía a este orden diferente tanto de la monarquía española, como de la vieja sociedad originaria? La conclusión de Lyra es históricamente cerrada y categórica: "La conquista destruye la sociedad socialista de los indígenas y sobre sus ruinas de un comunismo primitivo, echan las bases de una economía feudal" (323).

El otro dato interesante es que no hay una pregunta política acerca de si las viejas formas de propiedad y subjetividad (que no son solo anticapitalistas, sino también potencialmente anticapitalistas), allí donde hayan perdurado, pueden o no servir de puntal para una futura regeneración nacional y social del país ${ }^{13}$.

\section{Políticas de la memoria en Carmen Lyra}

En relación con la sociedad colonial hay varias contradicciones notables en el texto de Lyra, la primera, la indefinición de cuáles eran las formas de relación social dominante en la Costa Rica colonial. Lo curioso es que Lyra usando las categorías presentes y posibles en el universo

\footnotetext{
${ }^{13}$ Este olvido político de Lyra es un olvido recurrente de muchos marxistas latinoamericanos que leían el proceso de desarrollo de las relaciones capital-trabajo como un proceso necesario y civilizatorio, pero que ignoraban totalmente la clave de lectura presente en las cartas de Marx a Vera I. Zasúlich, en las cuales Marx interpelado por los socialistas rusos sostiene la posibilidad teórica que las formas comunitarias y no capitalistas de tenencia de la tierra típicas de las comunidades rurales sirvan de punto de apoyo para el desarrollo de un nuevo orden social revolucionario, esa fue la perspectiva que se desarrollo por ejemplo durante la revolución mexicana. Señala Adolfo Gilly: "Los campesinos de Morelos aplicaron en su estado lo que ellos entendían por el Plan de Ayala. Al aplicarlo, le dieron su verdadera contenido: liquidar revolucionariamente los latifundios. Pero como los latifundios y sus centros económicos los ingenios azucareros, eran la forma de existencia del capitalismo en Morelos, liquidaron los centros fundamentales del capitalismo de la región. Aplicaron la vieja concepción campesina precapitalista y comunitaria, pero al traducirla sus dirigentes en leyes en la segunda década del siglo XX, ella tomó una forma anticapitalista" (citado por Lowy, 1980, 414).
} 
ideológico del DIAMAT mezcla indistintamente relaciones esclavistas y feudales para caracterizar el orden social instaurado por los españoles. Señala: "Los españoles trajeron consigo sus costumbres feudales llenas de crueldad y la religión católica con su santo oficio" (306). Luego: "Establecieron el régimen esclavista que disfrazaron con la Ley de Encomiendas" (...) "Durante la Colonia es el régimen esclavista el régimen social que impera en Costa Rica. El señor, el amo dueño de esclavos hace trabajar al indio para subvenir sus propias necesidades y las de su familia y luego para vender en el mercado el excedente de los productos obtenidos" (307) "Trajeron a América su concepto feudal de propiedad" y "la explotación les permite tener un buen excedente que exportan a España" $(308)^{14}$.

Otro mecanismo ideológico interesante es que Lyra parece señalar que el atraso colonial de la sociedad costarricense es un producto directo del atraso venido de la sociedad española. Por ejemplo, al analizar la sociedad española señala que: "llevaba ocho siglos de guerra contra los moros" $(\ldots)$

"la agricultura, la industria y las artes no habían podido florecer" los españoles "no sabían manejar el arado o la bestia de labor ni trabajar en los talleres de las ciudades" (...) "La corrupción y la intriga reinaban la Corte de España y por lo campos y caminos andaban miles de vagabundos especializados en el arte de robar y asesinar" (319).

En general, España se presentaba como una sociedad asilada, encerrada y sometida a un terror religioso permanente: "Para defender a su pueblo de la herejía [se] levanta una rigurosa aduana intelectual entre España y el resto de Europa" (321). Estas aseveraciones curiosamente señalarían una nueva fractura subjetiva en la lectura de la Historia de Lyra, pero ahora siguiendo

\footnotetext{
${ }^{14}$ Este no es un ensayo, para retomar el debate entre distintos historiadores marxistas sobre el carácter de la colonización española y portuguesa, solamente tomaremos posición a favor de la interpretación que nos parece más convincente, que es la de Luis Vitale, este autor señala: "Otros autores (...) siguen sosteniendo que la colonización tuvo un carácter feudal. La gran propiedad territorial es uno de los argumentos que se han dado para demostrar el carácter feudal de la colonización. Este error proviene de identificar feudalismo con latifundio. Latifundios han existido tanto en el régimen esclavista como en el feudal y capitalista. El latifundio de la época colonial -a diferencia del feudaltuvo como objetivo la producción a gran escala de productos agropecuarios y mineros. Al latifundio colonial no le interesaba el autoabastecimiento - como al feudo- sino la producción para el mercado mundial. Otro argumento para insistir en el carácter feudal de la colonización se refiere a la explotación de los indios bajo el sistema de encomiendas. En rigor a la verdad, la encomienda tuvo más características esclavistas que feudales. Además, existen otros hechos, como el crecimiento de las ciudades, la centralización del poder a través del Estado colonial. Tampoco fue capitalista. Durante la colonia no hubo un modo de producción preponderante, sino variadas relaciones de producción precapitalistas y capitalistas embrionarias que, combinadas y articuladas, constituían una formación económica en transición al capitalismo." (Vitale, 1974).
} 
una de las temáticas decimonónicas de la geopolítica del conocimiento ${ }^{15}$, este discurso racista e imperial tiende a identificar el fracaso social y político de las sociedades latinoamericanas, como un producto de la herencia de la cultura latina europea ${ }^{16}$, las imágenes de la leyenda negra española (de factura anglo holandesa) y de la latinidad criolla disipada y vagabunda (de factura francesa) aparecen como parte del imaginario ${ }^{17}$ de Lyra.

Siguiendo por ejemplo el texto de Luis Vitale, España y Portugal antes de la conquista de América (1977) se puede reconstruir más bien otra España, influida por el progreso comercial árabe, con industrias y obreros en sus puertos, abierta a las influencias intelectuales de la época, una sociedad más bien con un capitalismo comercial incipiente que una cerrada y oscura sociedad feudal, que es la imagen que pretende transmitir Lyra. Pero para nuestro interés, más importante que estos rasgos de doble pensamiento ladino ${ }^{18}$ de Lyra, es que la lectura del tipo de sociedad que era la sociedad colonial costarricense va a ser la de una sociedad pobre, ignorante y aislada del

\footnotetext{
${ }^{15}$ Para Ramón Grosfoguel: "el punto central de las perspectivas epistémicas otras es la relación estrecha entre el lugar de la enunciación, esto es la geopolítica y corpo-política del sujeto que habla en las coordenadas del poder global y su estrecha relación con la producción de conocimientos" $(2005,151)$. Si se quiere seguir la forma en que la geopolítica del conocimiento incluyó la herencia latina en el campo de la diferencia colonial, conviene leer La idea de América (2007) de Walter Mignolo.

${ }^{16}$ Este discurso racista e imperial se ha reactivado por ejemplo con la acusación constante de que la crisis social y política griega es producto de la vagancia y la vida disipada de los trabajadores griegos, parte de su cultura mediterránea, compartida con España e Italia. Charles Andre-Udry, refutando el contenido racista de este discurso imperial señala: "Según las estadísticas de la OCDE y de la Eurostat, el tiempo de trabajo anual medio de los asalariados de la industria, del comercio y de la agricultura en 2008 era en Grecia de 2120 horas, o sea 470 más que los británicos. Muy lejos de los clichés. En 2007, el monto medio de jubilaciones estaba en $617 €$, y en 2009 el salario mínimo en $752 € . ”(2012,5)$

${ }^{17}$ Gallardo señala que imaginario puede ser utilizado: "como una sensibilidad social que está en la constitución misma de una sociedad que se produce a sí misma desde él. Designa por lo tanto a las instituciones sociales y a las lógicas que las animan (producciones), pero también a un determinado esfuerzo colectivo y personalizado por producirlas y asentarlas como condición de existencia social. El imaginario social se vincula con subjetividades que reproducen identificaciones inerciales (enajenadas para todas las formaciones sociales con lógicas de dominación) pero también con la virtualidad de autoproducción (creación) de identidades efectivas procesuales ligadas a un trabajo de resistencia personal y político.” (Gallardo, 2010).

18 “《ladino» indica, inicialmente, a quien, con independencia de su raíz cultural, aspecto racial y situación económica, desprecia y rechaza los valores indígenas de origen maya." (...) "Etimológicamente, «ladino» viene de latino, el que habla latín, o romance castellano, es decir el idioma de la dominación, de las élites. Si uno habla con las élites, sin pertenecer a ellas, por razones culturales o sociales, puede servir como mediador en beneficio propio entre los dominadores y los dominados. La función de mediación en beneficio propio en sociedades en guerra y de penuria, como han sido las latinoamericanas para los pueblos indios, conduce a asociar «ladino» con astuto, engañoso, labioso y también, con taimado. Esta última apreciación acerca del ladino corresponde a los grupos dominantes" (1993, 113114). Gallardo habla a propósito de un pensador de origen guatemalteco, aún así la reflexión es indudablemente extensiva al resto de formaciones económico sociales latinoamericanas, que han surgido sobre el genocidio y desprecio de las sociedades originarias, independientemente del nivel de desarrollo de fuerzas productivas y "democratización" (cualquier cosa que esto signifique en sociedades dependientes) que estas alcanzaron, es importante señalar que para Gallardo el "ser ladino" es sobre todo una actitud y bajo determinadas condiciones el ladino puede (pese a sus sensibilidad desgarrada) convocar y construir espacios de liberación social y nacional.
} 
mundo moderno (348), con una pobreza que incluso impedía cumplir solemnemente con los deberes religiosos $(338,339)$ pero justamente por eso igualitaria, nivelada hacia abajo producto de la indigencia. Lyra muestra la "verdad" histórica de esta tesis reproduciendo un conocido fragmento de Don Tomás de Acosta:

“Por la pobreza de la Provincia (...) el labrador, el artesano, el comerciante, el noble y el plebeyo, todos hacen sementeras de lo que han menester para el sustento de sus familias" (341). De allí Lyra derivará, usando como fuentes varios autores liberales y filo liberales como Soto Hall, Carlos Monge y José Francisco Trejos, varias conclusiones políticamente peligrosas, pero muy significativas para nuestro estudio. Las conclusiones a las que llega Lyra son que: "la Mita no alcanzó entre nosotros los caracteres de inhumanidad que en otras provincias” (331), los indios “disfrutaron de libertad en Costa Rica” y "colaboraron con las autoridades españolas en el gobierno de la provincia" (331), los tributos pagados por los indios "no eran excesivos" y sobretodo y lo más importante eran “concertados” (332).

Estas conclusiones de Lyra calzan perfectamente con lo que podríamos llamar el núcleo duro de las políticas de la memoria del comunismo "a la tica", cuya tesis fundamental reside en que la excepcionalidad costarricense puede rastrearse desde épocas de la colonia, la cual por su pobreza igualitaria condiciona la instauración de tradiciones e instituciones democráticas. Estas tradiciones democráticas son consolidadas en la época del liberalismo decimonónico. Los liberales costarricenses sinceramente democráticos, (y sobre todo distintos a los belicosos y autoritarios liberales centroamericanos), son los antecesores de los comunistas "a la tica" y éstos no habrían hecho más que "darle contenido socioeconómico" a esa tradición democrática.

Esta tesis es sostenida aún cuando en algunas de las descripciones históricas, se muestre la violencia clasista con la que fue constituida nuestra sociedad tanto en el periodo colonial, como durante la formación social republicana. Por ejemplo, la existencia de esclavos negros en las plantaciones de cacao (331), la posibilidad de la venta de indios en el mercado y su servidumbre penosa (332), la segregación racial y geográfica en la puebla de pardos (332), la piratería y el contrabando (333).

Filosofía de la Historia y políticas de la memoria en Rodolfo Cerdas Cruz

Rodolfo Cerdas Cruz juega un rol fundamental para comprender las políticas de la memoria del "comunismo a la tica", es el autor del "primer artículo marxista publicado en una revista 
académica" (Molina, 2007, 225), además, su trabajo "La formación del Estado en Costa Rica" (1967) "supuso la primera interpretación marxista de un período específico de la historia de Costa Rica” (226). Cerdas Cruz, fue un importante intelectual de izquierda política costarricense, referente ideológico del filomaoísta Frente Popular y probablemente el autor que más se preocupó por justificar su desafiliación y no afiliación política al PVP, aunque como veremos, sus elaboraciones lejos de disolver los tópicos fundamentales del comunismo "a la tica", los reforzaron y le dieron densidad.

Las conclusiones políticas que saca Cerdas Cruz, lo llevan a alejarse progresivamente de la izquierda política, ya para el año 1982, lidera un proyecto "de centro" ( es decir burgués) y finalmente se transformará en un metódico columnista de la prensa oligárquica hasta su fallecimiento. Analizaremos y criticaremos La crisis de la democracia liberal en Costa Rica (1972).

El libro contiene algunas hipótesis interesantes y resume muchos de los prejuicios que el comunismo "a la tica" construyó alrededor de la época liberal costarricense y la "excepcionalidad costarricense".

El Tercer Estado "a la tica". El Braulio Carrillo de Rodolfo Cerdas

Para Cerdas, Braulio Carrillo es el "liberal, más progresista, avanzado y visionario de la época" (168) el cual "con su dictadura positiva, democrática y constitutiva, logró consolidar la nacionalidad costarricense" (54) además "es él quien (...) le dará un impulso al cultivo del café, pero con una orientación y sentido especiales, hacia la pequeña propiedad" (31).

Según Cerdas, estas virtudes políticas y económicas de la época de Carrillo brotarían, del profundamente filosófico liberalismo de Carrillo: "Cuando Carrillo cita a Helvetius y Condillac, o cuando guarda doble ejemplar de las obras de Rosseau, no estamos frente a citas de erudición innecesaria, sino ante una influencia cultural y filosófica decisiva para la concepción suya de los problemas políticos" (32).

No está demás decir que para el joven Cerdas: "el materialismo francés presenta dos direcciones: Una proveniente de Descartes, que desemboca en el materialismo mecánico (...) y otra proveniente de Locke, que se constituye como elemento de la cultura francesa y desemboca, directamente en el socialismo" (30) y que justamente Condillac y Helvetius son las tendencias que van a "desembocar directamente en el socialismo comunismo" (31). 
Lo primero que indudablemente hay que señalar es que Cerdas, le da más poder a los libros y las influencias intelectuales de lo que podríamos aceptar, Cerdas concede a las ideas filosóficas un poder productivo (¡delinear con siglos de anticipación el desarrollo de un país!) que es difícil de aceptar.

El análisis que describe Cerdas Cruz, es básicamente un resumen de las ideas desarrolladas por Marx y Engels en La Sagrada Familia; lo que ignora y no señala nuestro autor es que normalmente la recepción de una determinada ideología filosófica y política en un país social y culturalmente más atrasado que el país de origen, produce una modificación productiva de las ideas mismas y de su universo de creación y alcance político.

Esta dimensión metodológica en la que una determinada formación social modifica una doctrina, es poco tratada por Cerdas quien de manera bastante esquemática tiende a ver que las ideas republicanas producen efectos similares o iguales independientemente de la formación social que las recepta ${ }^{19}$. Hay pues, algo de mala fe y de calco y copia. El argumento filosófico de Cerdas contiene un llamativo simplismo esquemático, pero también de colonialismo mental, pues coloca en la misma línea genealógica, el empirismo británico, el liberalismo criollo y el socialismo francoalemán. Esta operación ideológica busca justificar la "progresividad" histórica de los liberales costarricenses, para justificar la "original radicalidad" de las propias tesis. La operación aunque burda, tiene su lógica política.

Si bien Marx realizó una conexión entre la filosofía de Locke y el socialismo ${ }^{20}$, esta conexión tenía que ver con el desarrollo de las ideas políticas en el corazón de la Europa del siglo XVII y XVIII, es muy curioso que Cerdas Cruz, el cual es tradicionalmente tercermundista ${ }^{21}$ en sus análisis, quiera trasladar de manera mecánica esta genealogía, llama más la atención que sea justamente a Locke a quien quiera rescatar ${ }^{22}$.

\footnotetext{
${ }^{19} \mathrm{Si}$ se quiere estudiara la relación posible entre la teoría marxista y las peculiaridades de la recepción de ella en las formaciones sociales periféricas vale la pena leer El prólogo de Slavoj Zizek a Sobre la contradicción (2010) de Mao Tse Tung, El marxismo en América Latina (1980) de Michael Lowy y sobretodo el primer capítulo de Historia de la revolución rusa de León Trotsky (1932).

20“"existen dos tendencias en el materialismo francés: una tiene su origen en Descartes, la otra en Locke. La segunda tiende, principalmente, al desarrollo de la cultura francesa y desemboca directamente en el socialismo" $(1971,147)$.

${ }^{21}$ Tanto en El prólogo a la segunda edición de La formación del Estado en Costa Rica (1978), como en La hoz y el machete (1986) Cerdas va a defender que el esquematismo estalinista y su degeneración política en gran potencia imperial reside en el abandono de la orientación y la concepción presentes en las Tesis adicionales sobre los problemas nacional y colonial (1920), documento del II Congreso de la Internacional Comunista. Asimismo va a ver en el modelo de la revolución china, leída en clave maoísta la estrategia fundamental de la liberación social y nacional.

${ }^{22}$ Un pensador radical latinoamericano ha dicho a propósito de la obra de Locke y de lo que ha implicado su recepción en América Latina que: "Tanto el terror de Estado de los empresarios y militares latinoamericanos como la "guerra
} 
No creemos que sea un observación anacrónica nuestra crítica a Cerdas, ya que en el universo intelectual por él conocido se puede encontrar indicaciones para ponerse en guardia sobre el significado intelectual de Locke, por ejemplo, Jorge Plejanov (uno de los autores cuyos escritos más contribuyeron a la constitución del DIAMAT) reivindicaba como precursores a varios materialistas (Priestley, D’Holbach, Helvetius), pero no hay ninguna reivindicación de Locke, más bien hay burlas, Plejanov llama a Locke "inconsecuente, liberal inglés bien educado" (1960,1213).

La reivindicación hecha por Plejanov del sensualismo francés (Condillac, D’Holbach) tiene que ver con su carácter político-ideológico: "Holbach y los materialistas franceses de esa época no eran tanto los ideólogos de la burguesía como los ideólogos del tiers etat (...) Los materialistas formaban el ala izquierda del ejército ideológico del tiers etat" (131).

Si el Tercer Estado francés creó un belicoso y sensualista materialismo contra el espiritualismo y el ascetismo de la Iglesia y la aristocracia francesa, es claro que este elemento es inexistente en el pensamiento materialista de la burguesía británica. Ya en Locke -y más claramente en Hume- hay una clara inclinación por un acuerdo transaccional entre el Tercer Estado y la corona en materia política y por fundamentar el agnosticismo en materia filosófica ${ }^{23}$.

Cerdas mantiene a lo largo de su interpretación, una lógica abstracta, que solo logra comprender las sencillas dualidades: materialismo-progresimo/idealismo-conservadurismo, dualidad que opera para todo tiempo y lugar. Esta "lógica" en la mirada histórica es un rasgo que permanece en las distintas generaciones intelectuales de comunistas "a la tica".

Podríamos decir que Rodolfo Cerdas piensa con un esquema analógico, asume que las distintas corrientes filosóficas y políticas (materialismo, idealismo, teoría de la dependencia) tienen

preventiva" busheana fueron avisados en el inicio de la sensibilidad política moderna liberal por el inglés John Locke (...)[en este autor] la riqueza de cada cual se sigue de su trabajo individual, de modo que los grandes propietarios (...) deben ser defendidos por la legislación positiva (o la ley natural) en sus bienes e intereses como si se tratara de las vidas personales de sus dueños. Contra la propiedad privada, para Locke, se atenta incluso con el pensamiento. Y quienes ofenden la propiedad de otros (con la violencia usurpadora o la mendicidad o el imaginario de un mundo sin acumulación privada de capital) dejan de pertenecer a la especie humana y pueden (y deben) ser tratados como "fieras dañinas". En la gestación "liberal" del pensamiento moderno surge la figura de la no-persona, es decir de los individuos que por quebrantar la reproducción de un único orden racional posible (el centrado en la acumulación de capital), carecen de toda capacidad jurídica y, con ello, no admiten ninguna defensa legal" (Gallardo, 2007). Tomando en cuenta esta caracterización de Gallardo, tendríamos que señalar que es por lo menos problemático intentar vincular a un ideólogo del colonialismo racista, fundamentador filosófico de las guerras coloniales británicas y norteamericanas, con la tradición marxista, ni siquiera en sus versiones más tibiamente socialdemócratas.

${ }^{23}$ Para más detalles sobre las diferencias sociales y políticas del materialismo de Ilustración británica, francesa y alemana es muy ilustrativo la Introducción a la Filosofía de Kant de Lucien Goldmannn (1967, 27-42). 
similares efectos políticos, aunque se desplieguen en distintas formaciones sociales. Cerdas hace la siguiente operación: el marxismo europeo hereda la tradición anticlerical y republicana de la burguesía ilustrada francesa que tiene entre sus ideologías más importantes, al sensualismo radical (antiascético) de Condillac y este a la vez, tiene sus fuentes en el empirismo inglés; por lo tanto, la línea genealógica va de Locke a Marx, la afición de Carrillo a Condillac, Helvetius y Rosseau será garantía de sus virtudes republicanas y esta operación justificaría a la vez que Cerdas vea en Carrillo un antecesor de su pensamiento y una fuente para su propuesta política.

Liberalismo, librecambismo, fragmentación nacional

El esquema históricamente abstracto, utilizado por el socialismo colonizado y el comunismo "a la tica", en el cual se tiende a ver en el liberalismo oligárquico y en el librecambismo antinacional signos progresistas, o en el mejor de los casos, procesos "históricamente necesarios", es producto de su afán por querer comprender las condiciones latinoamericanas, como repetición de las que desarrolló el capitalismo europeo. Por ejemplo, Cerdas Cruz no señala como Carrillo es quien va a consolidar la fragmentación de la nacionalidad centroamericana y que el carácter autoritario de su gobierno se debía a la necesidad de garantizar la provincialización:

El proyecto nacional oligárquico plantea un ambiguo ejercicio del poder: un equilibrio entre la represión autoritaria y el consenso negociado, entre la exclusión y la participación, que permite a la oligarquía conservar su dominio y a los otros identificarse con el proyecto nacional y legitimarlo. (Quesada, 1998, 23).

Álvaro Quesada señala cómo antes de separarse de la Federación Centroamericana: "en los discursos de los jefes de Estado costarricenses, el término "nación" se refería siempre a Centroamérica y nunca a Costa Rica" $(1998,22)$. Media vez se ha concretado la separación de Costa Rica, las tendencias colonizantes al servicio de los grupos vinculados al comercio legal e ilegal con la metrópoli imperial, se exacerban tanto que en 1848 Castro Madriz envía instrucciones a su representante diplomático en Guatemala, Felipe Molina para que: "indagara si Inglaterra tenía interés en convertir a Costa Rica en un protectorado inglés" (22).

En las condiciones en las que se produce la emancipación nacional centroamericana, el librecambismo de los liberales fue siempre un elemento profundamente antipopular y antinacional, cuyos efectos sociales tendieron a fortalecer las predisposiciones provincialistas y ladinas. 
Nuestra opinión es que lo auténticamente progresista en la América Latina posindependentista, no es el pensamiento empirista y librecambista de impronta smithiana de oligarcas provinciales; sino las inaprovechadas alternativas nacional populares propuestas por José Artigas $^{24}$. Los efectos disociadores y antinacionales del librecambismo se sintieron en Centroamérica desde el inicio mismo de la independencia. Según Pinto Soria:

Lo cierto es que la situación económica de las masas populares no mejoró en nada con la proclamación de la Independencia. La exagerada importancia dada al libre comercio como instrumento de progreso económico produjo precisamente lo contrario (...) amplios sectores artesanales fueron especialmente golpeados por la crisis que vivió la industria textil frente a la competencia que les hizo la producción externa, acrecentada por esos años también a través del contrabando. $(1993,88)$.

Además de antinacionales, los liberales y librecambistas tenían fuertes elementos antipopulares y de racismo ladino. El mismo autor señala que: "en su afán modernizador, uno de los primeros decretos liberales de la Asamblea guatemalteca fue, por ejemplo, ordenar la extinción de todos los idiomas indígenas, extremo al que nunca llegó la propia Corona Española” (89).

Los efectos secesionistas, empobrecedores y racistas del librecambismo contrabandista y semicolonial de los liberales facilitó que las oligarquías provinciales instrumentalizaran con mucha facilidad, la auténtica indignación y malestar de las clases subalternas; artesanos y pueblos originarios, no en pocas ocasiones, se aliaron con la oligarquía poscolonial contra los republicanos liberales. Estas contradicciones y fuerzas sociales centrípetas son las que explican el surgimiento del separatismo de la Costa Rica de Carrillo. Mientras en Guatemala y El Salvador las fuerzas armadas morazánicas se batían buscando concretar una compulsiva unidad militar de Centroamérica, "un sector de las economías locales se había fortalecido y tomado muchas veces, a través del contrabando, contactos directos con el mercado exterior, lo cual profundizaría el proceso de parcelación en Centroamérica" (Pinto, 1993, 125).

El desarrollo, por un lado, del capitalismo agrario cafetalero y sus consiguientes procesos de diferenciación social y por otro, de la lumpen economía que fomentaba el contrabando inglés en el puerto de Puntarenas, son los elementos profundos del separatismo filobritánico y antinacional que socialmente representa el autoritarismo carrillista. La Costa Rica de Carrillo era

\footnotetext{
${ }^{24}$ José Artigas es uno de los más radicales próceres de la independencia hispanoamericana, Jorge Abelardo Ramos señala con gran lucidez que: "Artigas es el único caudillo de la Independencia que combina en su lucha la unidad de la Nación, con la revolución agraria y el proteccionismo industrial de los territorios bajo su mando" $(1968,153)$.
} 
la tierra del cafeto vallecentralino, nutrido del aislamiento de la guerra civil e impregnada de antimorazanismo, además del centro del contrabando pirata que socavaba las bases de la República Federal. Ya en esa época, se forjaban los prototipos de lo que las clases dominantes mostraran con venal orgullo como esencia geográfica-natural de "lo tico": una meseta llena de cafetos, indiferente a las luchas centroamericanas y un puerto con los ojos puesto en Inglaterra y cuya vista se enceguecía frente al pillaje pirata ${ }^{25}$.

Víctor Hugo Acuña señala que en la época de Carrillo empiezan a ponerse en pie dos de los mitos ideológicos fundantes de la identidad nacional costarricense: la "tierra de pequeños propietarios" y el "pueblo amante de la paz", este último eje aparece como una interpretación para minimizar los conflictos militares que se presentaron en este periodo (Acuña, 2002, 204-207). Rodolfo Cerdas señala que el modelo económico asentado en la producción cafetalera y en el divisionismo centroamericano no hará más que reforzar rápidamente, la subordinación de Costa Rica a las metrópolis anglo-yanquis, esta dependencia se verá hipertrofiada con la construcción del ferrocarril y la instauración del enclave bananero. (1972, 39-62).

Los bonapartes tropicales: Carrillo, Mora, Guardia

Lo más interesante de la propuesta teórica de Cerdas Cruz, para comprender la época liberal, es su caracterización de Braulio Carrillo, Rafael Mora y Tomas Guardia como "una especie de bonapartismo a nivel nacional" $(1972,53)$; se desea discutir y precisar esta caracterización, la cual es un importante aporte teórico de Cerdas, aunque siempre insuficiente en su alcance.

Es bueno señalar que la categoría bonapartismo es una de las categorías críticas claves de la teoría política de estirpe marxista. Analizando las características del régimen nacido del aborto de la revolución de 1848, Marx delinea las siguientes ideas sobre el régimen de Napoleón III:

Es bajo el segundo Bonaparte cuando (...) la máquina del Estado se ha consolidado (...). Bonaparte representa una clase, que es, además la clase más numerosa de la sociedad francesa: los campesinos parcelarios (...) Por cuanto existe entre los campesinos parcelarios una articulación puramente local y la identidad de intereses no genera entre ellos ninguna comunidad, ninguna unión nacional (...) son (...) incapaces de hacer valer sus intereses

\footnotetext{
25 "Para la tercera década del siglo era posible percibir un cierto incremento en la actividad de los puertos del Pacífico. Puntarenas, en Costa Rica, más cercano a los comerciantes ingleses del Callao y Valparaíso, tomó la delantera, y ya para 1833 tenía una actividad sin precedentes" (Pinto, 1993, 164). Aunque Belice era el centro del contrabandismo inglés, el puerto de Puntarenas jugaba también un rol de primer orden para facilitar y garantizar la burla de la alcabala marítima, solo el 30 de mayo de 1835 se había logrado detener un barco con 1300 quintales de palo de Brasil abordo (Pinto, 1993, 114).
} 
de clase en su propio nombre (...) No pueden representarse, sino que tienen que ser representados. Su representante tiene que aparecer al mismo tiempo como su señor, como una autoridad por encima de ellos, como un poder ilimitado de gobierno que los proteja de las demás clases (...) "Bonaparte no representa al campesino revolucionario, sino al campesino conservador" (...) como poder ejecutivo convertido en fuerza independiente, se cree llamado a garantizar el 'orden burgués'. (...) Bonaparte se reconoce al mismo tiempo, frente a la burguesía, como representante de los campesinos y del pueblo en general, llamado a hacer felices dentro de la sociedad burguesa a las clases inferiores del pueblo. Esta misión contradictoria del hombre explica las contradicciones de su Gobierno, el confuso tantear aquí y allá, que procura tan pronto atraerse como humillar, unas veces a esta y otras veces a aquella clase, poniéndolas a todas por igual en contra suya, y cuya inseguridad práctica forma un contraste altamente cómico con el estilo imperioso y categórico de sus actos de gobierno. (1978, 404-420).

Bajo la óptica del sentido común de una teoría política puramente liberal, el carácter no parlamentario, fuertemente centralizado en el ejecutivo y con permanentes recursos a la fuerza militar de los gobiernos de Carrillo, Mora y Guardia, alejarían a estos gobernantes de las tradiciones democrático-nacionales. Cerdas quiere reivindicar los elementos "progresistas" de estos gobiernos para su propia filiación comunista "a la tica" y por esto, recurre a la categoría de bonapartismo, para explicar la contradicción entre "progresismo" nacional y "formas autoritarias". Cerdas Cruz señala:

No es de extrañar la tendencia de estos pequeños propietarios a encontrar en el ejecutivo fuerte por lo menos un remedo de representación de sus intereses, dado que su característica predominante es su desorganización y atomización, contrariamente a la cohesión y organización que representan los grandes exportadores y comerciantes exportadores (...) [así] era lógico entender que no era en las instituciones propiamente parlamentarias donde podían [los campesinos parceleros costarricenses] encontrar un apoyo y una representación eficaz. Esas formas políticas tendían a convertirse en reducto de los grupos oligárquicos. $(1972,53)$.

Un hecho curioso es que si bien el joven Cerdas señala el carácter bonapartista de estos tres gobiernos, esto no lo hace poner en entredicho otro de los grandes mitos de la identidad nacional costarricense, la igualdad que se realiza entre la "sociedad de propietarios" y la "solidez democrática de las instituciones". El mismo Cerdas muestra cómo no hay ninguna razón para igualar democratización agraria e instituciones democráticas, podría haber pluralidad en la propiedad de la tierra y un régimen político no democrático, bonapartista; sin embargo, los 
comunistas "a la tica" y sus políticas de la memoria, siempre han preferido rodear los mitos ideológicos que enfrentarlos.

La ausencia fundamental de Cerdas en su análisis es obviar el carácter semicolonial, dependiente y balcanizado de la economía-sociedad costarricense, por lo cual no basta con caracterizar estos gobiernos como bonapartistas. Aquí, es necesario apelar a un aporte muy significativo que León Trotsky va a realizar para comprender los fenómenos bonapartistas en América Latina. Para el pensador ruso es necesario percibir que:

En los países industrialmente atrasados el capital extranjero juega un rol decisivo. De ahí la relativa debilidad de la burguesía nacional en relación al proletariado nacional. Esto crea condiciones especiales de poder estatal. El gobierno oscila entre el capital extranjero y el nacional, entre la relativamente débil burguesía nacional y el relativamente poderoso proletariado. Esto le da al gobierno un carácter bonapartista sui generis, de índole particular. Se eleva, por así decirlo, por encima de las clases. En realidad, puede gobernar o bien convirtiéndose en instrumento del capital extranjero y sometiendo al proletariado con las cadenas de una dictadura policial, o maniobrando con el proletariado, llegando incluso a hacerle concesiones, ganando de este modo la posibilidad de disponer de cierta libertad en relación a los capitalistas extranjeros. $(2000,163)$.

Kohan señala que en estos escritos tardíos:

De Trotsky [se utilizaba] una noción de "bonapartismo" bastante diferente de la de Marx -quien en 1852 sólo le atribuía una significación crítica y negativa- y mucho más cercana al concepto de "cesarismo" de Gramsci para quien este fenómeno político moderno, al igual que para Trotsky, podía tener una connotación positiva o negativa según la relación de fuerzas en la que se inscribiese. $(2003,35)$.

El carácter semicolonial de Costa Rica y la relación de fuerzas sociales entre las capas subalternas, las clases dominantes y el imperialismo, son los elementos que permiten determinar más precisamente, si el bonapartismo sui generis de Carrillo, Mora y Guardia significaban "las cadenas de una dictadura policial" o una "una cierta libertad en relación con los capitalistas extranjeros".

Y es que si Braulio Carrillo aportó las cadenas de la balcanización probritánica, Mora refleja más bien, una nueva relación de fuerzas que permite incluirlo en el unionismo militar centroamericano, lo cual es la forma más autentica que cobró el bonapartismo sui generis en la Centroamérica del siglo XIX. La invasión militar de los filibusteros y su proyecto de colonización 
capitalista, al servicio de los algodoneros esclavistas del sur, colocó al Ejército Nacional, con Rafael Mora a la cabeza, como una expresión peculiar de los campesinos costarricenses, pero también, reflotó las recurrentes tendencias unionistas de las capas subalternas centroamericanas, las cuales han bregado cada vez que hay una correlación de fuerzas favorable por darle solución a la tarea democrática inconclusa de reunificar la nación centroamericana.

Mora, ve claramente la necesidad de replantear una patria centroamericana unificada, capaz de producir progreso industrial propio (en esto Mora no deja de ser un liberal) y de resistir al sospechoso y agresivo vecino norteamericano, al cual aunque se le admira por su capacidad industrial y laboriosa, se le teme por su acre expansionismo militar.

"Todos pues debemos interesarnos y participar en nuestros reveses y prosperidades. El golpe que a uno inmole herirá a todos. El aislamiento sería una aberración salvaje; la inacción un crimen, la desunión, el suicidio infantil de nuestras débiles nacionalidades" (Mora citado por Ovares, 1993, 43).

En el victorioso regreso del Ejército Nacional, Mora les aconsejará a los campesinos trocar: "el fusil por vuestro arado, pero preservadle siempre dispuesto para defender la ley, la concordia nacional, que es nuestra fuerza y la patria centroamericana" (36). En esta famosa proclama de Juanito Mora va acompañando al unionismo militar centroamericanista, una clara resonancia jeffersoniana con su idea de milicia civil.

Se ve pues en Mora y también en el General Cañas, el aporte costarricense a la estirpe de los unionistas militares centroamericanos y por lo tanto, también ellos serán presas de las deficiencias de la actitud del unionismo militar, que le costaron la vida a Morazán.

Aunque las fuerzas filibusteras fueron derrotadas por la acción conjunta de los cinco ejércitos centroamericanos, y la necesidad de una Asamblea Constituyente que reunificara Centroamérica, liquidara el latifundio y protegiera al artesanado, estaba claramente planteada; los cinco ejércitos regresaron tranquilamente a sus respectivas provincias sin trastocar los fundamentos sociales de la balcanización.

Mora será presa de esta insuficiencia política y social, caerá victima de las conspiraciones de la oligarquía cafetalera, la correlación de fuerzas retrocedía nuevamente para las clases 
subalternas ${ }^{26}$. Para garantizar plenamente la balcanización extranjerizante, las clases dominantes reflotaron un nuevo bonaparte balcanizador: Tomas Guardia.

La consolidación del bonapartismo liberal y la sombra de las clases subalternas

En la época cuando gobierna Guardia y su grupo (Soto, Esquivel, etc.), se institucionaliza la "democracia liberal" al servicio de las compañías extranjeras y la oligarquía cafetalera y se consolida la dependencia externa haciéndose "presente en nuestro país el capital financiero internacional, con los empréstitos ingleses para la construcción del ferrocarril (...) y con las concesiones a Minor Keith y (...) a la United Fruit Co., [en lo referente a la] penetración [del] capital norteamericano" (Cerdas, 1972, 58). Existe en el país una extensa y notable bibliografía analítica, testimonial y literaria sobre la economía de enclave bananera en la zona atlántica (Kepner y Soothill, 1949; Casey, 1979) y los efectos semicoloniales y antipopulares que tuvo en nuestra economía-sociedad (Aguilar, 1983; Acuña, 1984) por lo que no se profundizará en ello. Queremos más bien enfocarnos en el desgarrado clima cultural de la época liberal, marcada por la actividad del Grupo del Olimpo:

Una pequeña élite de escritores, intelectuales y políticos, cuya juventud y formación coincidió con la consolidación del estado liberal en la década de 1880 [Ellos] elaboraron un modelo de cultura nacional en varios campos, entre ellos las letras [e] iniciaron las primeras reflexiones sobre la literatura nacional y su posibles modelos y temáticas. (Ovares, 1993,112).

Los miembros del Grupo del Olimpo se debatirán entre las "bellas letras" del modernismo afrancesado y la fabricación de las "Concherías" y su lenguaje "distintivamente nacional”; en este mismo tiempo histórico, se inicia la descomposición del bonapartismo liberal y la aparición propiamente del pensar radical costarricense. El elemento de calidad de esta época es el ingreso del capitalismo norteamericano e inglés en su fase imperialista y monopólica, lo que generará mayor presión sobre las economías dependientes y mayor imbricación con las élites

\footnotetext{
${ }^{26}$ Es importante señalar que la iconografía "nacional" en relación a la campaña de 1856, se empieza a configurar como una medida política e ideológica para rechazar/contestar la re aparición del unionismo militar centroamericano, es decir como un elemento balcanizador. Palmer anota que es en 1885 cuando fue reconstruida -como origen imaginario de la nación- la guerra contra Walker, el mismo año el general Rufino Barrios "había declarado la Unión de Centro América e hizo planes para actuar mediante las armas si el acuerdo de paz fallaba (...) La declaración de guerra de Barrios (...) fue tomado por el estado y la oligarquía costarricense como una seria amenaza, de modo que a fines de marzo de ese año fue necesaria la movilización inmediata del pueblo" (Ovares, 1993, 47). En uno de esos clásicos mecanismos de neutralización política que efectúan las clases dominantes, la "canonización" de Mora y Santamaría tenía como objetivo justificar un cada vez más firme aislacionismo anticentroamericano.
} 
locales. Pero con el despliegue de las relaciones de producción, también surgirá la rebeldía de las clases subalternas, lo cual imprime una fuerte impronta antiimperialista al pensar radical surgido en esa época. Se podrían resumir en cuatro puntos las características generales que cobrará este modelo capitalista dependiente en América Latina: A principios del siglo XX y finales del siglo XIX, se construyó una economía de índole exportadora, especializada en la producción de unos cuantos bienes primarios.

Una gran parte de la plusvalía creada es drenada hacia las economías centrales, mediante el sistema de precios en el mercado mundial, prácticas financieras impuestas, o por la exportación de beneficios del inversionista extranjero.

Las clases dominantes locales tratan de resarcir esta pérdida de riqueza social, aumentando el valor absoluto de la plusvalía creada por los trabajadores agrícolas y mineros; esto es, los someten a un régimen de superexplotación.La superexplotación del trabajo constituye así el principio fundamental de la economía subdesarrollada, con lo que eso implica, en cuanto a bajos salarios, desempleo, analfabetismo, desnutrición y represión policíaca ${ }^{27}$.

Conclusión: Otro pensar radical, otra política de la memoria

Estos serán los fundamentos materiales de los que surgirán las formas más elementales del pensar radical costarricense. Resistiendo este verdadero castigo a la fuerza de trabajo, es que cobran luz las primeras formas de organización popular, aunque no desarrollen inicialmente una visión de mundo acabada.

En la Costa Rica de fines de siglo XIX:

El grueso de las clases explotadas lo constituyen los pequeños propietarios rurales, cuyas fronteras siempre inciertas con el proletariado agrícola se dibujan aun más con el avance de las crisis económica y social" (...) "A pesar del peso numérico que en este período tiene la pequeña burguesía rural, y a pesar de existir una relativa tradición de lucha entre los peones (movilización en 1889 contra el fraude electoral), la característica (...) es

\footnotetext{
${ }^{27}$ Como señala con preclaridad Quijano: "La clasificación racial de la población y la temprana asociación de las nuevas identidades raciales de los colonizados con las formas de control no pagado, no asalariado, del trabajo, desarrolló entre los europeos o blancos la específica percepción de que el trabajo pagado era privilegio de los blancos. La inferioridad racial de los colonizados implicaba que no eran dignos del pago de salario. Estaban naturalmente obligados a trabajar en beneficio de sus amos. No es muy difícil encontrar, hoy mismo, esa actitud extendida entre los terratenientes blancos de cualquier lugar del mundo. $\mathrm{Y}$ el menor salario de las razas inferiores por igual trabajo que el de los blancos, en los actuales centros capitalistas, no podría ser, tampoco, explicado al margen de la clasificación social racista de la población del mundo." $(2000,291)$
} 
el predominio urbano de los acontecimientos políticos y sociales. (Amador, 1980, 64).

Nuestro planteamiento es que en este primer momento, se pueden detectar un fenómeno que luego se integrarán en las comprensiones del pensar radical de las clases subalternas. En primer lugar, una asimilación bastante embrionaria de la posibilidad de una defensa radical popular del voto frente a las maniobras y manipulaciones en las alturas de los partidos-clientelas de los caudillos oligárquicos; esta asimilación proviene de la primera irrupción de las masas populares de manera autónoma en la historia costarricense: la lucha del 7 de noviembre de 1889 contra el fraude electoral.

No es de despreciar que con la aparición de la peonada cafetalera, fueran cada vez menos frecuentes en la vida política los “cuartelazos", los cuales constituían ecos espasmódicos del viejo unionismo militar. A la vez, es importante señalar que pese a la recurrencia de los sectores dominantes a cargar de bonapartismo el régimen político, éstos no lograron instaurar una férrea dictadura militar que aplastara a las clases subalternas, que se habían puesto en movimiento. Según Amador, en la Costa Rica liberal:

No existió jamás realmente un régimen democrático parlamentario. El régimen era de tipo bonapartista débil. El Bonaparte era elegido, reelegido o simplemente impuesto: Pero la misma necesidad de recurrir a una cobertura electoral era una prueba de los límites a que se enfrentaban nuestros dictadores electos. $(1980,65)$.

Parece muchísimo más agudo interpretar las imperfectas, pero reales libertades democráticas conquistadas a finales del siglo XIX e inicios del XX, como un logro de las primeras irrupciones de los sectores populares, los cuales pese a su carencias organizativas y analíticas, "le marcaron la cancha" a la oligarquía cafetalera y a sus caudillos, que atribuir, en contra de toda la evidencia histórica, estas libertades políticas a las bondades y virtualidades de los liberales, como hacen Cerdas, Mora y los intelectuales orgánicos de la izquierda política educados en las cuadrículas mentales del comunismo "a la tica".

Asimismo, el acercamiento que nos presenta Amador a lo que podríamos llamar la dimensión democrático-ciudadana del pensar radical nos plantearía una forma diferente de entender la historia de las instituciones políticas costarricenses, no guiada por una lógica "en cascada" de ideas liberales e instituciones liberales, como la presenta Cerdas y en general los ideólogos del comunismo "a la tica", sino como el resultado de una lucha, de un combate entre 
fuerzas sociales que pueden entender o no los objetivos de la lucha que emprenden, pero cuyo resultado es siempre inesperado, indeseado por los fuerzas en combate, pero sobretodo un resultado abierto a la acción histórica de los sujetos.

Por cierto, es importante señalar que la dimensión ciudadana del pensar radical costarricense, puede tener también una adulteración políticamente peligrosa y es esta forma la que con más frecuencia será utilizada por las clases dominantes costarricenses, para expropiar políticamente las movilizaciones de los sectores populares. El 7 de noviembre de 1889, la lucha contra el fraude electoral en la década de los cuarentas y la convocatoria al referéndum sobre el TLC en el 2007 tienen en común este elemento, en los tres casos vemos una política y una estrategia de las clases dominantes, diseñada con el objetivo de adulterar y apropiarse de una bandera democrática-ciudadana para lograr mediatizar la fuerza social de las clases subalternas que amenazaba con desbordarse.

La historia ideológicamente narrada por Cerdas Cruz y Carmen Lyra, la historia ideológicamente construida por el comunismo "a la tica" es la institucionalización de esta subjetividad fragmentada en el seno de las clases subalternas.

\section{Bibliografía.}

Acuña, V. (1984) La huelga bananera de 1934. San José: CENAP-CEPAS

Aguilar, M. (1983) Carlos Luís Fallas. San José: Editorial Porvenir.

Casey, J. (1979) Limón, 1880-1940: un estudio de la industria bananera en Costa Rica. San José: Ed. de la Universidad de Costa Rica.

Cerdas, R. (1964). Formación del estado en Costa Rica (1821-1842). San Pedro de Montes de Oca, C.R.

(1972) La crisis de la democracia liberal en Costa Rica. San José: EDUCA.

(1986) La Hoz y El Machete. San José: EUNED.

Engels, F. (1975). Ludwig Feuerbach y el fin de la filosofía clásica alemana. (Cuadernos de pasado y presente; 59). Córdoba, Argentina: Siglo XXI.

Fallas, C y Lyra, C. (2000) Ensayos políticos. Introducción de Iván Molina Jiménez. San José: Ed. de la Universidad de Costa Rica.

Gallardo, H. (1993) Fenomenología del Mestizo. San José: DEI

Gramsci, A. (1967) La formación de los intelectuales. (Trad. José Aricó). México: Ediciones Grijalbo.

Goldmannn, L. (1974) Introducción a la filosofía de Kant. (Trad. José Luís Etcheverry) Buenos Aires: Amorrortu.

Grosfoguel, R. (2005) Actualidad del pensamiento de Césaire: redefinición del sistema-mundo y producción de utopía desde la diferencia colonial en Césaire, A. -et. al.- (2005) Discurso sobre el colonialismo. Madrid: Akal Ediciones.

Kepner, Ch. y Soothill, J. (1949) El imperio del banano. México: Ediciones del Caribe. 
Kohan, N. (2002) Ni calco ni copia ensayos sobre el marxismo argentino y latinoamericano. La Habana: Ediciones Ciencias Sociales.

(2003) Marx en su (Tercer) Mundo. Hacia un socialismo no colonizado. La Habana: Centro de Investigación y Desarrollo de la Cultura Cubana Juan Marinello.

Lyra, C. (1972) Obras Completas. Tomo I. San José: Patria Libre.

(1977) Relatos Escogidos. Selección, prólogo, notas y cronología de Alfonso Chase. San

José, Costa Rica: Ed. de la Universidad de Costa Rica.

Lowy, M. (1980) El marxismo en América Latina. (Trad. Oscar Barahona y Uxoa Doyhamboure) México: Editorial Era.

(1997) Redención y utopía. El Judaísmo libertario en Europa central. Buenos Aires, El Cielo por Asalto.

Mao, T.; Zizek, S.; Brotons Muñoz, A. (2010). Sobre la práctica y la contradicción. (Revoluciones: textos clásicos de la mano de pensadores críticos; 3). Madrid, España: Akal.

Marx, K. y Engels, F. (1971) La sagrada familia. (Trad. Carlos Liacho) México: Grijalbo.

(1978). Obras Escogidas. III Tomos. Moscú: Editorial Progreso.

Merino, J. (1996) Manuel Mora y la democracia costarricense: viaje al interior del partido comunista. Heredia: EUNA.

Mignolo, W. (2007) La idea de América Latina. La herida colonial y la opción decolonial. Barcelona: Gedisa.

Mora, E. (1970) Introducción al marxismo-leninismo. San José: Ediciones Revolución.

Mora, M. (1980) Discursos 1934-1979. San José: Editorial Presbere.

Ovares, F. (1993) La casa paterna: escritura y nación en Costa Rica. San José: Ed. de la Universidad de Costa Rica.

Plejanov, J. (1964) Obras Escogidas. (Trad. Patricio Tombo, II Tomos). Buenos Aires: Editorial Quetzal.

Pinto Soria, J.C. (1993). El régimen colonial (1524-1750).

In: Historia general de Centroamérica. Madrid: Sociedad Estatal Quinto Centenario.

Quijano, A, (2000) Colonialidad del poder, eurocentrismo y América Latina. En Lander, E. (2000) (comp.) La colonialidad del saber: eurocentrismo y ciencias sociales. Perspectivas Latinoamericanas. Buenos Aires: CLACSO.

Quesada, A. (1998) Uno y los Otros. San José: Ed. de la Universidad de Costa Rica.

Ramos, J. (1968) Historia de la Nación Latinoamericana. Buenos Aires. CFE.

Trotsky; L. (1929) Stalin: el gran organizador de derrotas. Ediciones internacionales Sverldov. Madrid: España (1932) Historia de la revolución rusa (Trad. Andreu Nin). Madrid: Ediciones Sarpe. (2000) Escritos Latinoamericanos (2ª edición). Buenos Aires: CEIP León Trotsky.

\section{Revistas y Artículos de Revistas.}

Acuña, V. (2002) La invención de la diferencia costarricense. 1810-1870. Revista de Historia 45 / Escuela de Historia, Universidad Nacional, Centro de Investigaciones Históricas de América Central, Universidad de Costa Rica, 191-228.

Amador, F. (1980). Páginas de nuestra historia revolucionaria. Revolución, 1, 20-36.

Dal Maso, J. (2007) La ilusión gradualista. A propósito del nacionalismo, la retórica "socialista" y el marxismo en América Latina. Revista Lucha de Clases $N^{o}$ 6, 109-130.

Gallardo, H (1980). Del quehacer filosófico. Revista de Filosofía de la Universidad de Costa Rica, XVIII (47), 61-77. 
(2007) Lucha social, Pinochet y la producción de justicia. Revista Digital Pensar en América Latina www.heliogallardo-americalatina.info/Joomla/ (2009) Notas sobre las izquierdas políticas. Carácter y vigencia de la izquierda en América Latina. En Pensar en América Latina. Ubicación: http://heliogallardoamericalatina.info/index.php?option=com content\&task=view\&id=129\&ltemid=9

http://heliogallardo(2010) Educación para la descolonización del imaginario. Ubicación: americalatina.info/index.php?option=com content\&task=view\&id=184\&ltemid=1

Herrera Zúñiga, J.R. (2008). La producción socio-histórica del comunismo "a la tica". [San José, C.R.].

Herrera Zúñiga, J.R. (ene.-ago. 2009). Pensar radical, pensar colonizado: una mirada al marxismo costarricense. Revista de filosofía de la Universidad de Costa Rica; Vol.47, no.120/121; 45-53. Herrera Zúñiga, J.R. (2011). Ocho preguntas sobre el comunismo "a la tica". En http://revistaamauta.org/2011/07/ocho-preguntas-sobre-el-comunismo-\%E2\%80\%9Ca-la-tica\%E2\%80\%9D/ Molina, I. (2008) La influencia del marxismo en la historiografía costarricense. A contracorriente. Una revista de historia social y literatura de América Latina. Vol. 5, No. 2, Winter 2008, 220236.

Udry, Ch.A. (2012) Grecia: ¿La cuna de que Europa? En Revista Viento Sur. Ubicación: http://www.vientosur.info/documentos/Udry Grecia-1.pdf

Vitale (1974) Modos de producción y formaciones sociales en América Latina. En La haine. Ubicación: http://www.lahaine.org/b2-img/vitale1.pdf

Vitale (1977) España y Portugal antes de la conquista. En Archivo Chile. Ubicación: http://www.archivochile.com/Ideas Autores/vitalel/7lvc/07histuni0003.pdf 